\title{
When age becomes a plus: Seniors and Cognitive Reserve
}

\begin{abstract}
Cognitive Reserve alludes to gain, resistance, plasticity and is the functional correlative of neuroplasticity and a potential protection factor, which could explain why some patients may show the same pathology but quite different clinical manifestations. Among the activities considered as promoters are studies, work, physical and social activities. Although there are surveys or tables that seek to measure these factors and reflect this reserve in an index, this can be a quite reductionist strategy. Given the increasing ageing of the population, added to the active elders paradigm, programs addressed to seniors are carried out; it is important to consider that gains are accumulative and dynamism must be promoted from earlier ages. The sample for this work consisted of 30 seniors (60-87years) from the Region of Valparaíso, Chile. The CRIq was applied to the participants to measure the CR index and no differences were found between men and women. The purpose of this work is to describe the activities that promote reserve, carried out from 18 years onwards by 30 autonomous and cognitively competent seniors. It is held that it is not the type of activity that matters, but rather the frequency and the length of the execution period that turns into advantages for the persons. The data submitted reveal that seniors never failed to frequently execute some of the activities. That is, they had the habit of being active along their whole lives. This mechanism could be considered as a kind of dynamo where the greater input of promoting activities would make possible better conditions of the nervous system, but it does not have an easy storage as it is in continuous use. For this reason, gains depend on the active habit of execution, its early start, diversity of activities and permanence during the whole life span.
\end{abstract}

\author{
Volume 6 Issue 3 - 2021
}

\author{
Carla Rimassa,' Carla Taramasco² \\ 'Faculty of Medicine, Interdisciplinary Territorial Health \\ Research Center (CIISTe), Universidad de Valparaíso, Chile \\ ${ }^{2}$ Faculty of Engineering, Labitec, Universidad de Valparaíso, Chile \\ Correspondence: Carla Rimassa, Faculty of Medicine, \\ Interdisciplinary Territorial Health Research Center (CIISTe), \\ Labitec, Campus San Felipe, Universidad de Valparaíso, Chile. La \\ Troya/Camino El Convento S/N. San Felipe,Valparaíso, Chile, Tel \\ 56342431200,Email carla.rimassa@uv.cl
}

Received: June 07,202I | Published: November 17,2021

Keywords: cognitive reserve, neuroplasticity, seniors, ageing, life span

\section{Introduction}

The term Cognitive Reserve (CR) has appeared linked to several different concepts, from being a protection factor, ${ }^{1}$ cognitive storage, ${ }^{2}$ resistance capacity, ${ }^{3}$ plasticity, ${ }^{4}$ neural mechanisms ${ }^{5}$ to resilience, flexibility and brain black box. ${ }^{6}$ Its first mention is attributed to Katzman et al., ${ }^{7}$ who carried out a post mortem histological study of the brains of subjects that had been controlled during life. The authors observed that there were brains with similar histologic characteristics, but some subjects did manifest the Alzheimer diseases clinically and others did not. Furthermore, the latter had a bigger brain volume. Regarding this the researchers pointed out that: "these people may have had incipient Alzheimer's disease but escaped loss of large neurons, or alternatively, started with larger brains and a greater number of large neurons and thus might be said to have had a greater reserve." Later on Stern $^{8}$ differentiated the functional aspect and the brain structure, keeping the first to define CR. In the rehabilitation field, CR has been proposed as the functional correlation of neuroplasticity, and as a potential protection factor that could explain why "several patients may show the same pathology but present a quite different clinical manifestation. Such differences may be conditioned by the kind of activities carried out by the subject during his life, providing a greater resistance to deterioration, the more reserve promoting activates having been carried out. Therefore, symptomatology can be more intense in some of them, as well as lesser in others." ${ }^{9}$

Now, among the activities that are considered as CR promotors, although not exclusive, are studies, work, physical and social, and from a decade ago different instruments (surveys and scales) ${ }^{10-14}$ have appeared which pretend to measure the promoting factors, weight them and reflect this reserve in an index. However, considering that the $\mathrm{CR}$ must be understood as a variable accumulative mechanism that depends on the frequent and systematic performance of these activities, which implies that habit to practice them or to incorporate new ones. To attempt to measure them to reflect the phenomenon in an index might be an excessively reductionist approach.

In this sense, it is necessary to highlight two elements that can influence the CR. On the one hand, the complex process of individual ageing which involves the biological changes that take place (cell, molecular) among others, and taking place along the life of persons from birth to death" ${ }^{15}$, although "those changes are not linear not uniform and their link to the age of a person in years is mostly relative. Although some septuagenarians enjoy excellent health and function perfectly, others are fragile and need considerable help. ${ }^{16}$ This is relevant due to the increasing ageing rate of the population, because "people live longer all over the world. Now, for the first time in history, most of the population has a life expectancy equal or over 60 years." 16

\section{Material and methods}

The sample for this work consisted of 30 seniors (60-87years) from the Region of Valparaíso, Chile. The CRIq was applied to the participants to measure the $\mathrm{CR}$ index and no differences were found between men and women. The purpose of this work is to describe the activities that promote reserve, carried out from 18 years onwards by 30 autonomous and cognitively competent seniors.

\section{Results}

The data stated in Table 1 shows the average years of execution of each activity by gender and the total of the sample. The range column shows the data extreme limits. 
It must be stressed that there were no significant differences in the CR of senior men and women in this study. It is relevant to remember this when observing Table 1 , because among the ten activities mentioned, only in four do women show more years on the average for their execution (housework, intellectual games, social activities and handicrafts). It is also seen that work activities and the use of technologies show a marked difference in favor of men. The distinction between reading newspapers or magazines and books is made because that the latter need more time and dedication: and this was an aspect to be differentiated. In all cases. In all instances, car driving referred to manual drive cars. The questions about intellectual games refer to solving puzzles, Sudoku, brainteasers, alphabet soup, card games among others. Now, the main point of this Table is to center on the number of years in which the seniors carried out their activities, because none lasted less than 10years on the average.

Table I Average years of execution of cognitive reserve promoting activities

\begin{tabular}{|c|c|c|c|c|c|}
\hline \multirow{2}{*}{ Activities } & \multicolumn{5}{|c|}{ Years of execution averages } \\
\hline & Women & Range & Men & Range & Total \\
\hline Studies & 14,46 & $(12-17)$ & 16,06 & $(12-24)$ & 15,26 \\
\hline Work & 25,26 & $(0-55)$ & 41,86 & $(32-6 I)$ & 33,56 \\
\hline Reading & & & & & \\
\hline $\begin{array}{l}\text { Newspapers and } \\
\text { magazines }\end{array}$ & 29,3 & $(0-56)$ & 32 & $(0-62)$ & 30,65 \\
\hline Books & 11,13 & $(0-40)$ & 18,53 & $(0-59)$ & 14,83 \\
\hline Housework & 19,2 & $(4-60)$ & 2,93 & $(0-22)$ & 11,06 \\
\hline Car driving & 21,8 & $(0-48)$ & 22,33 & $(0-55)$ & 22,05 \\
\hline Intellectual games & 20,26 & $(0-52)$ & 17,86 & $(0-55)$ & 19,06 \\
\hline Use of technology & 6,6 & $(0-30)$ & 15 & $(0-32)$ & 10,8 \\
\hline Social activities & 24 & $(I-55)$ & 22,73 & $(0-55)$ & 22,36 \\
\hline Handicrafts & 23,4 & $(2-56)$ & 13,6 & $(0-59)$ & 18,5 \\
\hline Ages & 68,93 & $(60-82)$ & 70,13 & $(61-87)$ & 70,03 \\
\hline
\end{tabular}

\section{Discussion}

Although the length of years of study is usually linked to greater $\mathrm{CR}$, it seems that all promoting activities impact on gains. This aspect is relevant, because it reinforces that it is not the type of activity but the frequency and the extent of time of the execution which turns into gains for the persons. But there is an aspect that it is essential to highlight rather than focus on the differences in the activities that are carried out in greater or lesser degree by men and women. In this sense, whether the activities may have been carried out exclusively or in parallel, the important point in the data shown is that the persons in this study never remained idle, without carrying out any of the activities. That is to say, they had the habit of being active during their whole lives. ${ }^{17-19}$

\section{Conclusion}

Neuroplasticity is the phenomenon at the base of the cognitive reserve. This term may not be the most adequate because, on the one hand "reserve" suggests the concept of storage and on the other "cognitive" directs attention to certain functions, eluding others of great impact. Broadly speaking, the frequent and systematic performance of study, work, social and physical activities impacts favorably in the increase of experiences and their effect at the brain level. This mechanism could be interpreted as a kind of dynamo, in which the greater input of promoting activities makes possible better conditions for the nervous system. But there is no easy storage as the mechanism is in continuous use. Although the more diverse the range of experience may be, it may strengthen the brain structure.
An aspect is unavoidable and seems to be the greater challenge: the execution cannot stop although important aspects that sustain the CR gains are the execution habit, early start, accumulation of the years of practice, diversity of activities and their permanence along time within the vital cycle. Thus, each new learning, (a dance, a recipe, a sentence, a poem, a game, a movement or exercise, a new path, another landscape, new people, among many others), are challenges that generate gains. Therefore, the more years of performance of CR promoting activities, the larger investment in the potential protection mechanism. Then, when does age become a plus? When the years are invested in future life quality.

\section{Acknowledgments}

This research was partially supported by FONDECYT Regular 1201787 (Multimodal Machine Learning approach for detecting pathological activity patterns in elderlies).

\section{Conflicts of interest}

The author states there are no conflicts of interest.

\section{Funding}

None.

\section{References}

1. Carnero-Pardo C. Educación, demencia y reserva cerebral. Revista de Neurología. 2000;31(6):584-592.

2. Foresight Mental Capital, Wellbeing Project. Final project report. London: The Government Office for Science; 2008

3. Stern, Y. Cognitive reserve. Neuropsychologia. 2009;47(10): 2015-2028

4. Rodríguez M., Sánchez J. Reserva cognitiva y demencia. Anales de Psicología. 2004;20(2):175-186.

5. Stern Y. Cognitive reserve in ageing and Alzheimer's disease. Lancet Neurology. 2012;11(11):1006-1012.

6. Katzman R, Terry R, DeTeresa R, et al. Clinical, pathological, and neurochemical changes in dementia: A subgroup with preserved mental status and numerous neocortical plaques. Annals of Neurology. 1988;23(2):138-144.

7. Stern Y, Arenaza-Urquijo E, Bartrés-Faz D, et al. Whitepaper: Defining and investigating cognitive reserve, brain reserve and brain maintenance. Alzheimer's \& Dementia. 2021;16(9):1305-1311

8. Stern, Y. What is cognitive reserve? Theory and research application of the reserve concept. Journal of the International Neuropsychological Society. 2002;8(3):448-460.

9. Rimassa C. Medición de Reserva Cognitiva: estudio en una muestra de adultos chilenos. Revista Chilena de Fonoaudiología. 2019; 18: 1-9.

10. Valenzuela M, Sachdev P. Assessment of complex mental activity across the lifespan: development of the lifetime of experiences questionnaire (LQE). Psychological Medicine. 2007;37:1015-1025.

11. León I, García J, Roldán L. Construcción de la escala de reserva cognitiva en población española: estudio piloto. Revista de Neurología. 2011;52(11):653-660.

12. León I, García-García J, Roldán-Tapia L. Escala de Reserva Cognitiva y envejecimiento. An psicol. 2015;32(1):218-223.

13. Nucci M, Mapelli D, Mondini, S. The cognitive reserve questionnaire (CRIq): a new instrument for measuring the cognitive reserve. Aging Clinical and Experimental Research. 2011;24(3):218-226. 
14. Rami L, Valls-Pedret J, Bartrés-Faz D, et al. Cuestionario de reserva cognitiva. Valores obtenidos en población anciana sana y con enfermedad de Alzheimer. Revista de Neurología. 2011;52:195-201.

15. Alvarado AM, Salazar MA. Análisis del concepto de envejecimiento. Gerokomos. 2014;25(2):57-62.

16. Organización Mundial de la Salud. Informe Mundial sobre Envejecimiento y Salud. Washington DC: WHO/FWC/ALC/15.01. 2015 .

17. Organización Mundial de la Salud. Envejecimiento activo: un marco político; Grupo Orgánico de Enfermedades No Transmisibles y
Salud. Mental Departamento de Prevención de las Enfermedades No Transmisibles y Promoción de la Salud Envejecimiento y Ciclo Vital: OMS; 2002.

18. Rimassa C. La capacidad de producir textos escritos sintácticamente complejos y su relación con la reserva cognitiva de los sujetos adultos que los produce (Tesis Doctoral, Pontificia Universidad Católica de Valparaíso). 2014.

19. Cognitive Reserve Index. CRIq questionnaire. 